\title{
An Exploration of Risks Involved in Managing Supplier Portfolio in Multinational Companies Operating in Indonesia
}

\author{
Nova Sepadyati ${ }^{*}$
}

\begin{abstract}
Outsourcing applications have widely used and regarded as a primary strategic management tool by firms. However, particularly in the Fast Moving Consumer Goods (FMCG) industry, most companies have at least once declined from a renewing contract with the same service provider. There have not been any studies regarding risk management in a buyer-supplier relationship in multinational companies (MNCs) from developed countries operating in an emerging country, particularly in Indonesia. The purpose of this qualitative study is to find out how MNCs in the FMCG sector in Indonesia choose their suppliers, risk perceived, and how they manage their relationship with different suppliers to ensure their performance. Buyer's previous experience, time/cost pressure, and company's culture proved to influence companies in selecting suppliers. Key risks perceived by companies mainly regarding unperformed suppliers, supplier's opportunistic behaviour, and unstable economic/political condition. To ensure a supplier's performance, companies need to set different relationship positioning for each activity outsourced through a proper type of contract and aligned performance measurement. Moreover, a formal supplier rating has not found in all companies, let alone supplier development initiatives.
\end{abstract}

Keywords: Supplier selection, supplier evaluation, supplier portfolio, FMCG MNCs, buyersupplier relationship, Indonesia.

\section{Introduction}

Outsourcing is a process of shifting an existing business activity, including the relevant assets to a third party (Lonsdale and Cox [1], which companies implemented because of various reasons. Outsourcing has been in business literature for many years, mainly done to achieve economy of scale and lower the cost. For instance, Nokia outsourced $30-40 \%$ of mobile production (Shy and Stenbacka [2]). On the other hand, the overall level of satisfaction with outsourcing among firms remained below 50\% (Kang et al. [3]). Particularly in FMCG industry, Wilding and Juriado [4] found that $74 \%$ of consumer goods companies' respondents have at least once declined from a renewing contract with the same service provider, showing dissatisfaction at some point. Therefore, a better understanding of risks in managing supplier portfolio is needed. However, only a few works of literature explicitly explain these risks. Therefore, finding the main risks from companies' perspectives and what can be done to face those risks is expected to get a new insight, especially for practitioners in the FMCG industry. The majority of the research on buyer-supplier relationship has been done mostly in developed countries such as USA (Car and Pearson [5]; Narayanan et al. [6]), UK (Cousins et.al [7]; MacKerron et al. [8]), Europe (Schmitz and Platts [9]), or

\footnotetext{
1 Faculty of Industrial Technology, Department of Industrial Engineering, Petra Christian University, Jl. Siwalankerto 121-131, Surabaya 60238, Indonesia. Email: nova.s@petra.ac.id

* Corresponding author
}

Japan (Sako [10]) and also in emerging country as China (Liu [11]; Tang and Rai [12]). Hence, it is interesting to research in a unique setting, where multinational companies came from developed countries but operating in an emerging country such as Indonesia.

Firstly, the study intends to understand how MNCs operating in an emerging country as Indonesia set their strategy in selecting their key suppliers. In the FMCG industry, the supplier selection process becomes more demanding as changing customer preferences require a broader and faster supplier selection (de Boer et al. [13]), as products sold very quickly. Before the supplier selection process begins, three essential needs to be considered: buying conditions, sourcing strategy, and sourcing structures (Cousins et al. [7]). There are three types of buying conditions, i.e. the straight re-buy, the modified rebuy, and the new-task buying. Concerning sourcing strategy, Kraljic [14] develops a product portfolio model used in purchasing as a basis for classifying purchases and setting purchasing policy, which will determine the model and the amount of effort put into the final selection (Cousins et al. [7])). Despite other models available, Kraljic's approach still became a leading method to what practitioners regard as "operational professionalism" (Gelderman and Weele [15]), practised by large companies such as Shell, Alcatel, Philips, Akzo Nobel, Océ, and Siemens (Van Weele [16]). Besides, other scholars proposed models using some similar dimensions or recommendations with Kraljic's (Gelderman and 
Weele [17]). Lastly, sourcing structure ranging from single, multiple, delegated or parallel, which is determined by-product or service purchased in Kraljic matrix (Cousins et al. [7]).

The supplier selection process includes four steps, starting from determining requirements, determine criteria for evaluation, obtaining information, and make the selection. Determining requirements contains product or service specification that needs to be provided by suppliers, which will serve as the basis for the request of Request for Proposal (RFP), Request for Quotation (RFQ), or Request for Information (RFI) (Cousins et al. [7]). Thus, it will be more as sorting and not a ranking process (de Boer et $a l$. [13]). In determination criteria for the evaluation phase, traditionally done by choosing a supplier with the lowest bid price. However, the practice is seen as unreasonable nowadays (Cousins et al. [7]). Talluri and Narasimhan [18] suggest strategic dimensions and capabilities of suppliers such as stress on quality management practices, process capabilities, management practices, design and development capabilities, and cost reduction capabilities considered into the decision-making process. Moreover, Cousins et al. [7] categorise the criteria for supplier into five main competitive priorities (cost, quality, delivery, flexibility and others). Also, high-performing firms are likely to have a smaller number of measures than low performers, using only more relevant standards to the context (Cousins and Lawson [19]).

Once criteria decided, obtaining relevant information began (McIvor [20]). Information gathered from suppliers, supplier visit, or supplier performance measures for existing suppliers (Cousins et al. [7]). However, although costly and time-consuming, the surest way to spot the best supplier is through firsthand information, by entrusting a large number of vendors with commodity activities before outsourcing more sensitive activities to the best vendors (Barthelemy [21]). Finally, making supplier selection is conducted. By having different criteria, even different ones such as quality and price can create more complexity to the supplier selection decision (Golmohammadi and Mellat-Parast [22]).

Secondly, the study aims to understand the risks in a buyer-supplier relationship. Before understanding the risks, the study will discuss portfolio approaches to supplier relationship, which is a base of supplier relationship management (Caniels and Roeleveld [23]). Leonidou [24] classifies a wide array of influence strategies into six groups legalistic, coercive, reward, expert, referent, and informational. On the other hand, Tang [25] classifies types of supplier relationships by the strategic importance of the part to the buyer and buyer's bargaining: vendor, preferred supplier, exclusive supplier, and partner. Tang's model similar to the Kraljic Matrix, where both consider the business importance on business but expand the definition of complexity in the supply market in Kraljic as buyer's bargaining power.

On the contrary, Olsen and Ellram [26] classify nine types of relationships based on the strength of a relationship and relative supplier attractiveness. However, too many factors influencing each category and $3 \times 3$ matrix makes it harder to define boundaries, for example, between "average" and "high" level. Furthermore, also based on Sako [10]'s work, Cousins et al. [7]) develop a map based on two critical variables for management of relationship, dependency and certainty (Figure 1). Cousins' model is preferred since the model consider not only the level of dependency but also the level of certainty in the relationship. The model is complementing Kraljic Matrix, which already considered as the standard of purchasing portfolio models.

The buyer-supplier relationship is dynamic since there are instances in which the buyer or supplier can change the business environments and modify the subsequent supplier relationship (Tang [27]). Therefore, it is essential to understand the risks in a buyer-supplier relation. The immediate risk is poor quality, which could be caused by an inappropriate or incorrect detail in work specifications in service level agreements (SLAs). However, even if the company set SLAs, a supplier may behave opportunistically by providing the firm with the least satisfactory level of provision or team that still allows them to comply with the terms of the contract (Lonsdale and Cox [1]). Another risk is raising prices by suppliers, which found as the most common way of suppliers' leverage (Lonsdale and Cox [1]). The last risk found is late delivery. For example, poor communication between manufacturer, carrier, warehouse, and customer operations has often caused difficulty and delay in logistics management (Razzaque and Sheng [28]).

Thirdly, the study will explore how MNCs in the FMCG sector in Indonesia manage risks found in supplier portfolio to ensure their performance. Firms from developed countries have long-established repertoires for alliance activity than firms from emerging markets, which usually have less experience in exploring and attempting to exploit partnership opportunities (Hitt et al.[29]). Moreover, many MNCs are struggling to develop successful strategies in emerging markets, because of the absence of specialized intermediaries, regulatory systems, and contract-enforcing mechanisms in emerging markets-"institutional voids" (Khanna et al. [30]). 


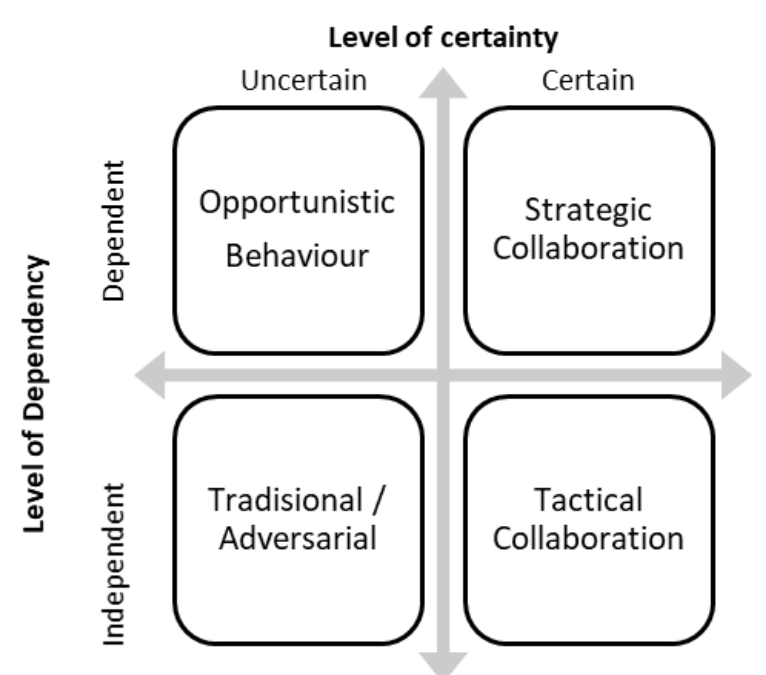

Figure 1. Strategic relationship positioning model (SRPM) (Cousins et al. [7])

Previous research leading suggestions in handling risks in supplier relationship are a contract, performance measurement, information and communication management, and disruption risk management. Contract development is crucial, as a contract is an investment whose value becomes apparent if the relationship with the supplier becomes sour (Barthelemy [21]). There are different types of potential contract relationships, where control and flexibility trade-off is always present in any contract made. Regarding the content of the contract, Barthelemy [21] defines the best contract are: precise, complete, incentive-based, balanced, and flexible. Mc. Ivor et al. [31]) found that flexibility is crucial as it needs to enable the updating of performance metrics on an agreed basis between client and supplier. Moreover, they found that performance measurement can remove inefficiencies from processes both before outsourcing and during the outsourcing relationship, even proved to add values in four ways, i.e., decision making, communication, visibility, and motivation (Cousins et al. [32]). By defining the process steps upfront, both parties can define the scope of each step, the expected outcome of each step, the review process, and the process to resolve any conflicts or mismatched expectations. More importantly, doing so would allow both parties to set expectations for contract negotiation and exit options (Sodhi and Tang [33]).

In managing performance measurement in Procurement department, it is essential to choose whether to be evaluated based on efficiency (focusing on transactions, workload, specific procedure, headcount) or effectiveness (supplier development, value analysis, forward buying programmes, and lead time reduction (Cousins et al. [7]]). Companies have to maintain sufficient knowledge inside the firm (in people and information systems) to be able to control specialist suppliers (Quinn and Hilmer [34]). Loss of control is a significant risk to quality, caused by a lack of capability or inactive vendor management. It is crucial to retaining a small group of managers to handle the vendor (Barthelemy [21]) for each activity outsourced. Moreover, Lawson et al. [35] found that managerial communication and technical exchange contribute to buyer's performance improvement. Surprisingly, Chopra and Sodhi [36] found that underestimating the possibility of a disruptive event is far more expensive in the long run than overestimating the likelihood; therefore the multi-supplier strategy is the most common approach for reducing supply chain risks(Tang [25]). Going from one DC to two can dramatically reduce fragility without significantly losing too many of the benefit of pooling recurrent risks; especially real for large companies (Chopra and Sodhi [36]). Other strategies in mitigating supply disruption are safety stock, responsive pricing, or supply chain segmentation to improve profits and reduce supply chain fragility(Sodhi and Tang [33]).

\section{Methods}

\section{Conceptual Framework and Methodology}

A conceptual framework is drawn from literature, complementing in answering research questions (see Figure 2)

Transparent methodology to conduct the research is structured based on the research onion model (Saunders et al. [37]). The study is based on a familiar topic, but intend to explore specific settings, which is MNCs in FMCG industry operating in Indonesia. The study is exploratory research; therefore, an inductive approach. It is considered as inductive because the conceptual framework made from literature as a base (Figure 2), but the conclusion will be made after conducting the interviews, gaining secondary data, and identifying differences and similarities between each case. A qualitative study was done to understand the subjectivity in humans in their social (organisations) settings, not to test the hypothesis to create laws.

A case study strategy is chosen for several reasons. Primarily due to its suitability, most research questions asked are "how" questions, and there was little control over events, which suits critical characteristics of a case study (Yin [38]). Since the study will limit the study in supplier selection and buyersupplier risk management, a case study will able to provide an in-depth account of events, relationships, experiences or processes occur in the context chosen (Denscombe [39]). Also, a case study is flexible, to collect data from several sources in capturing the 


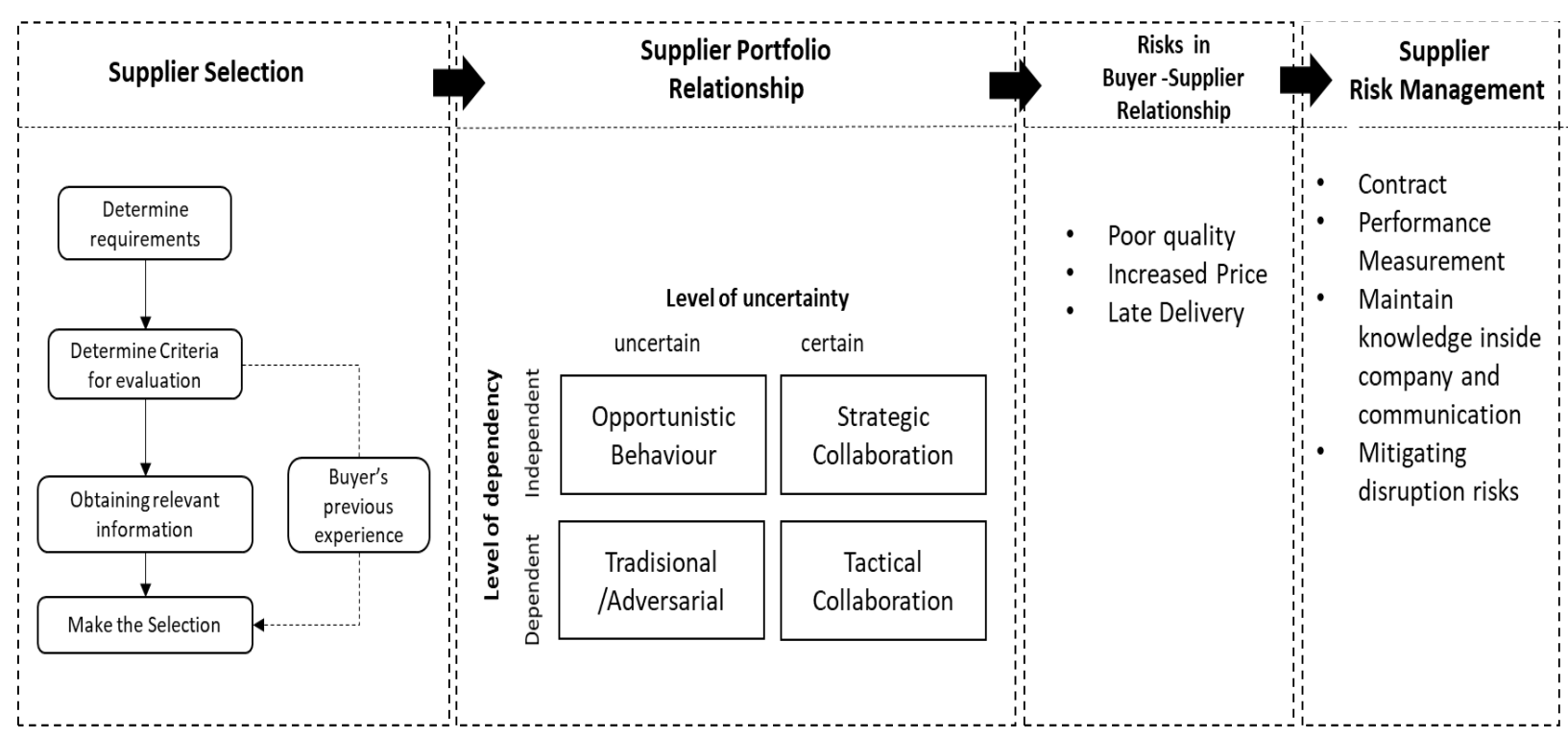

Figure 2. Conceptual framework

Table 1. Basic information of companies

\begin{tabular}{llll}
\hline \multicolumn{1}{c}{ Description } & \multicolumn{1}{c}{ Company 1} & \multicolumn{1}{c}{ Company 2 } & \multicolumn{1}{c}{ Company 3 } \\
\hline Type of products & food & non-food & food \\
International operations (worldwide) & 115 countries & 16 countries & 50 countries \\
Number of employees & $308,000(2018)$ & $28,000(2016)$ & $90,000(2018)$ \\
Department(s) interviewed & Logistics & Marketing & Sales \\
& Procurement & Procurement & Logistics \\
Number of interviewees & 2 & 2 & 3 \\
Presence in Indonesia & 1971 & 1991 & 2010 \\
Key activities outsourced & Transportation & Perfumes & Transportation \\
& Warehousing & Packaging & Warehousing \\
& & & Distribution channel \\
\hline
\end{tabular}

complexity of real condition (Denscombe [39]). Moreover, the case study fits well with the needs of smallscale research through focused work on a few sites (Denscombe [39]). Gaining access to companies is highly unpredictable and can be time-consuming, which makes the quantitative study as survey impractical. Furthermore, regarding the critical evaluators of the research, a case study is a common approach in social science projects. Lastly, the study will focus on supplier selection and managing risks in a buyer-supplier relationship based on current and previous companies' experience, which best capture by case study (Benbasat et al. [40]). The research mainly will focus on one point in time, known as cross-sectional (Saunders et al.[37]). The longitudinal study requires data collected across a more extended period will be not feasible in this research, considering 3-month time limitation.

\section{Data collection and Analysis}

The study will use interviews as the primary source as it allows flexibility in an exploratory study. Observation is unfeasible options because of the limited access of the researcher, while questionnaires need sufficient amount of samples which is not feasible because of time limitation. Moreover, regarding the types of interviews, a semi-structured interview is preferable as it prompts guidance in discussion while still giving freedom of variability depending on the flow of conversation. The case studies were chosen from both food and non-food companies to get a broader perspective. As a mean to enhance confidence in the findings, data triangulation was done by doing interviews with more than one person from each company, so does with several theories found in the literature to construct theoretical triangulation. The interviews set up using the funnel model, starting from broad questions (procurement structure and main activities outsourced), to more detailed questions as interview progress (Voss et al.[41]) (questions related explicitly to Supplier Selection, Risks in Managing Supplier Portfolio, and Managing Risks in Supplier Relationship).

Regarding the secondary data, documentation and archival records would be collected. Documents collected are core list for supplier reduction (Company 2) and 
performance control report documents (all companies). Other documents, such as contracts are prohibited due to companies' privacy reasons. Even though all companies interviewed from FMCG industry, their background is different. Both Company 1 and 2 are well-known for their business on down stream (consumer-packed) products. Meanwhile, Company 3 built and excels in the upstream business, which is commodity products. The purpose of this study is to develop a concept, which produced based on interpretation and meaning behind the text, which are characteristics of Grounded Theory (Denscombe [39]). The study involves three MNCs with their basic information as below describe in Table 1.

Before analyzing interview results, data documentation and coding is needed. Documentation involves transcription of tape recordings, which ideally done as soon as possible after the interviews to maximize recall and follow-up gaps in data (Voss et al. [41]). Data coding involves broke interviews into components for data reduction (Saunders et al. [37]). The researcher will use three steps in the coding scheme, i.e. open coding, axial coding, and selective coding (Corbin and Strauss, [42]). Data analysis begin with analysing data within cases before analysing crosscase patterns (Voss et al. [41]). Both analyses will use graphs as the simplest yet most effective way to do the analysis.

\section{Results and Discussions}

Based on interviews, open coding done by researcher manually by identifying keywords found from interviewee's answers. Moreover, axial coding done separately for each company, before cross-case coding done as follows, structured as per research questions, followed by selective coding:

\section{Supplier selection}

Two steps are taken to understand how MNCs in the FMCG sector in Indonesia choose their suppliers. First, open coding was done by researcher manually by identifying keywords found from interviewee's answers. Then, axial coding by making connections between keywords found. Axial coding consists of: the conditions that give rise to it, context, handling strategies, and consequences of those strategies (Corbin and Strauss [42]). Sourcing supplier strategy and supplier selection would be the central phenomenon. Open and axial coding done for all three companies, before constructing final axial coding (Figure 4) by making connections from three companies.

By comparing results from all interviews, there are several similarities identified. All companies differ suppliers by considering things such as their impact on the business, how many available suppliers in the market, and difficulty in switching to new suppliers. These key points are matched with Kraljic's [14] portfolio model. Moreover, it is intriguing to find that even though in different ways, companies' culture or internal politics mentioned in the supplier selection process. In company 1, it is the reason why it may take the long process in a tough negotiation, "It may be because of culture from company's origin country, which makes us more prudent in making choices". Company 2: "sometimes we imported a particular material from X (company's origin country), which must be not cost-efficient". While in company 3: "We have never even considered changing the current WH provider since it was chosen by the highest level of people since this company built". Therefore, this company's 'culture' will be added to factors influencing supplier selection (Figure 8).

Furthermore, buyer's previous experience influence on supplier selection as McIvor [20] theory strengthhened by a statement from company 3: "I usually use the ones that I know for years, based on my experience with previous companies too. Another similarity is on criteria in selecting supplier, which mainly use, although not all companies interviewed have structured supplier selection process, they only use operational metrics such as cost, quality, and delivery. Nevertheless, in exceptional cases, as to reduce perfumes supplier in Company 2, creativity, matching capability, service and turnaround, consumer insight, and criticality to current business are factors to choose suppliers. Furthermore, there is no specific multi-criteria decision making used in the selection process. The main tools used are using weighing factors.

On the other hand, there are several differences perceived. Both company 1 and 2 have a procurement team in charge of the supplier selection process, resulting in a more structured and organised selection process. Moreover, the company's pressure on cost reduction sensed stronger both in Company 2 and 3. This condition makes them compromising quality (even Company 3 explicitly choosing price over quality) while Company 1 would agree to take a more extensive selection process if needed. Strategic dimensions as quality management practices (Talluri and Narasimhan [18]) or soft selection criteria as a willingness to share information (Kannan and Tan [43]) did not found in all companies. Nevertheless, only Company 1 mentioned a feeling of trust as supplier selection criteria, which also suggested by (Ellram[44]). To summarize, FMCG companies choose their suppliers not always in a structured process, while their supplier selection criteria mainly based on operational criteria (cost, 


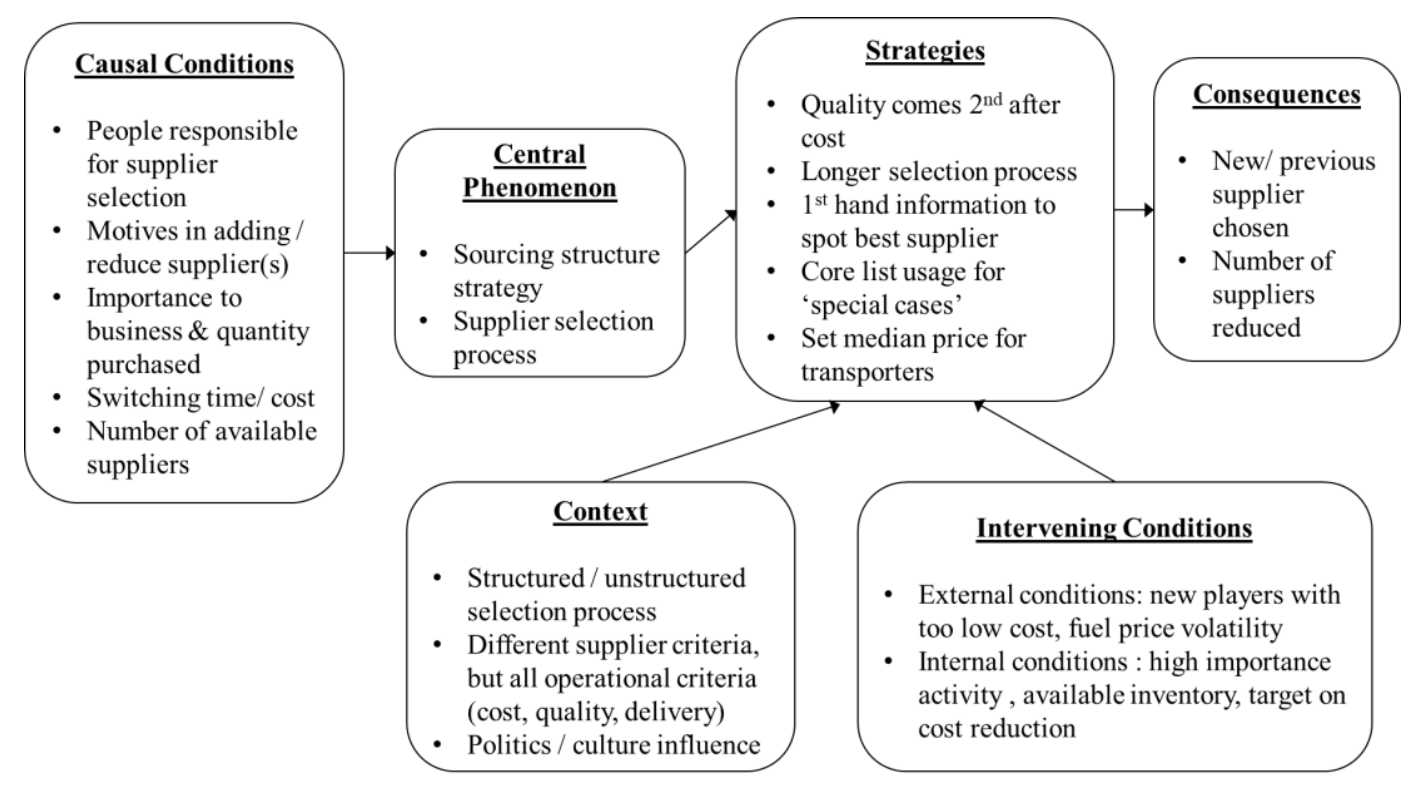

Figure 3. Final axial coding - supplier selection

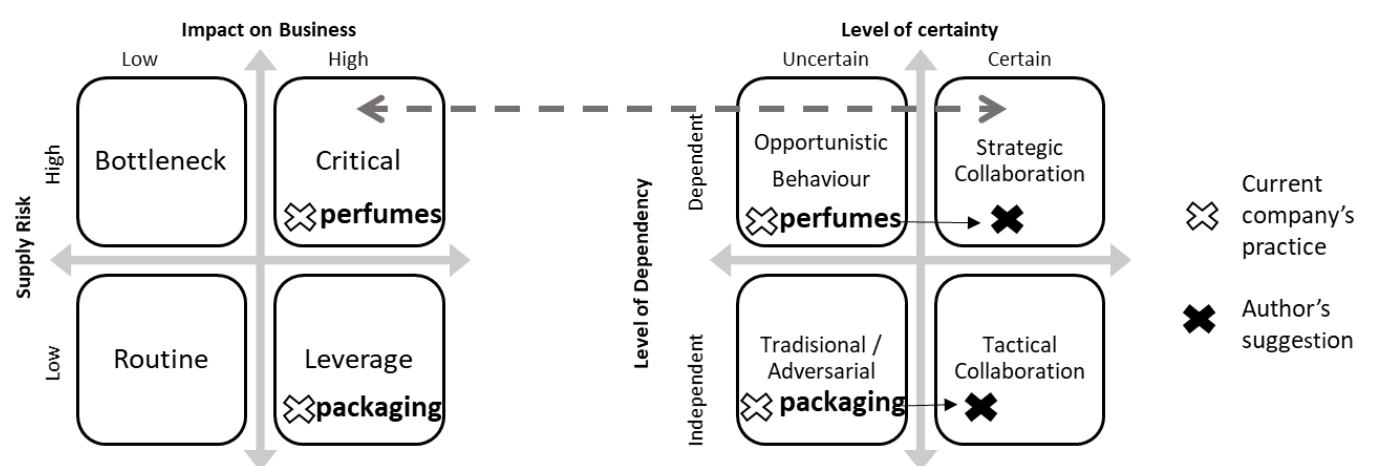

Figure 4. Kraljic matix Company 2

Figure 5. Strategic relationship positioning model Company 2

quality, delivery). Moreover, there are some conditions influencing evaluation processes found, such as the buyer's previous experience or politics inside the company. The key things are mapped in the diagram as depicted in Figure 3.

\section{Critical risks in managing supplier portfolio}

In understanding companies' supplier portfolio, each activity outsourced in every company will be put into Kraljic, before drawing the Strategic Relationship Positioning Model. Kraljic is needed to understand the importance of activities outsourced based on interviews done. For example, in company 2, both perfumes and packaging are seen as essential products for production, and the quantity is high. The statement "it is not always easy to get a capable packaging supplier, we have used more suppliers before, and there are only three of them that has a low rate of defects. However, it is much easier than finding a perfume supplier, that is why we need to import the perfumes from other countries", showing high supply risk for perfume and low-medium risk for packaging. These considerations put the packaging into leverage, while perfumes into critical items in the Kraljic Matrix (see Figure 4).

Moreover, the Strategic Relationship Positioning Model is built to check the suitability of the current company's relationship approach. For example, in company 2 (Figure 5) perfumes procured from small numbers of suppliers (high dependency); and not set any contract in place (low uncertainty). Therefore, these practices lead to opportunistic behaviour, while perfumes as strategic items need to be controlled using strategic collaboration. To be aligned, Company 2 should put a contract in place. Relationship implemented in Company 1 has aligned, while both Company 2 and 3 can improve how they manage their relationship. McCutcheon and Stuart [45] find only a few supplier relationships that warranted being called alliances, despite the full use of the term. As logistics manager stated: "we are trying to keep a close relationship with several partners, but there will always be a boundary between different companies, that is why we need the con- 


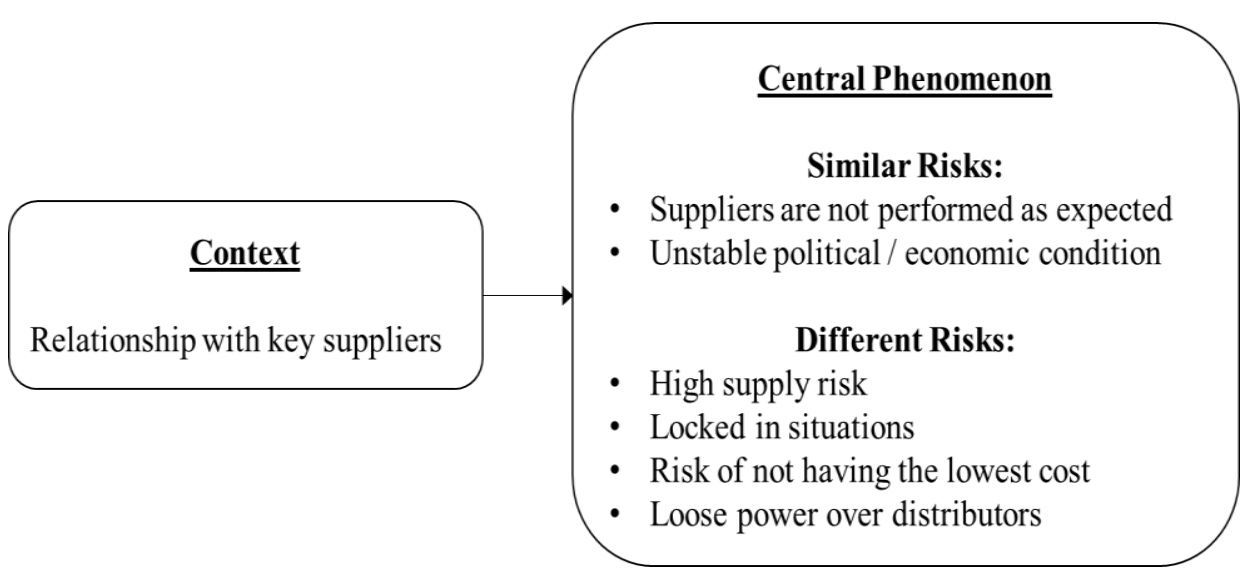

Figure 6. Final axial coding - Risks in managing supplier portfolio

Table 2. Structured rating method (Schmitz and Platts [9])

\begin{tabular}{lll}
\hline & Company A & Company B \\
\hline Rating method & Weighted scoring & Weighted scoring \\
Scale & 0 (worst) to 100 (best) & 1 (worst) to 10 (best) \\
& $<80$ for six months: QC certification suspended; no & $>9$ : letter of recommendation \\
& new orders. Improvement plan requested<80 for one & $>7.5$ : contact suppliers, discuss problem areas, \\
Actions & year: loss of QC, find a replacement for supplier & and if necessary, initiate program development \\
\hline
\end{tabular}

tract". Therefore, it is critical for companies to not only mention their key suppliers as partners but to change the relationship according to SRPM explored before.

After understanding the supplier portfolio, the author explores risks involved in supplier portfolio. Open coding and axial coding is done in each company before cross-cases, resulting in final axial coding (Figure 6.) All companies mentioned the risks of suppliers not performing as promised, whether in quality, price, or delivery. Moreover, both company 1 and 3 consider the risk of extreme political or economy condition in Indonesia. Besides, company 2 stated the risks of getting locked into global contractdeal.

Interestingly, there are more risks found by company 2 , and 3 compare to company 1 . The relationship in Company 1 is aligned (Figure 5), while both Company 2 and 3 need to change their relationship strategy. Therefore, it is logical to say that a thorough relationship strategy planning is expected to minimize various risks in managing supplier portfolio.

\section{Managing risks to ensure suppliers' performance}

There are differences found in IT infrastructure and procurement department involvement in three companies examined. For example, Company 3 does not have both procurement involvement and IT infra- structure to manage the suppliers, while Company 1 and 2 have high procurement involvement. However, Company 1 has more structured contracts and more updated information (for example, webtracking), allowing them to have better control through its suppliers. By not having the capabilities or not actively manage the vendor will endanger the company losing control of suppliers, leading to poor quality of service (Barthelemy [21]).

Two similarities found after analysing cross cases. All companies avoid a single supplier, which seen as the most common approach to reduce risks (Tang [25]). However, other risk mitigation efforts did not found in all companies, which can be far more expensive in the long run than overestimating the likelihood (Chopra and Sodhi [36]). Other strategies in mitigating supply disruption are safety stock, responsive pricing to entice consumers to switch their demand from unavailable to available products (Sodhi and Tang [33]), or supply chain segmentation to improve profits and reduce supply chain fragility. All companies put updating information as a priority, whether from group or to ask 'the right person' from an outside organization.

Issues related to the contract were not particularly prominent in all companies. For example, one interviewee (company 1) said: "A proper contract is the most important thing to control our relationship". Another interviewee (company 3), when asked, said: "We do not feel we need any contract since it may burden us in the future. We have rarely had a pro- 


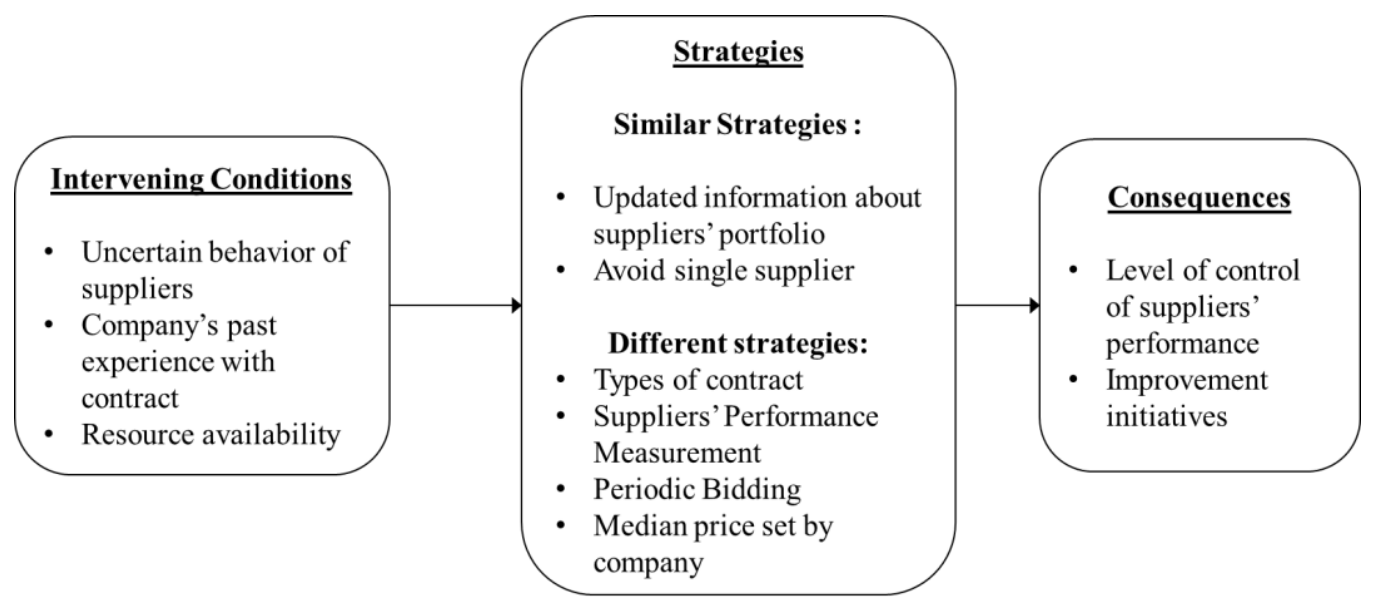

Figure 7. Final axial coding-Managing risks to ensure performance

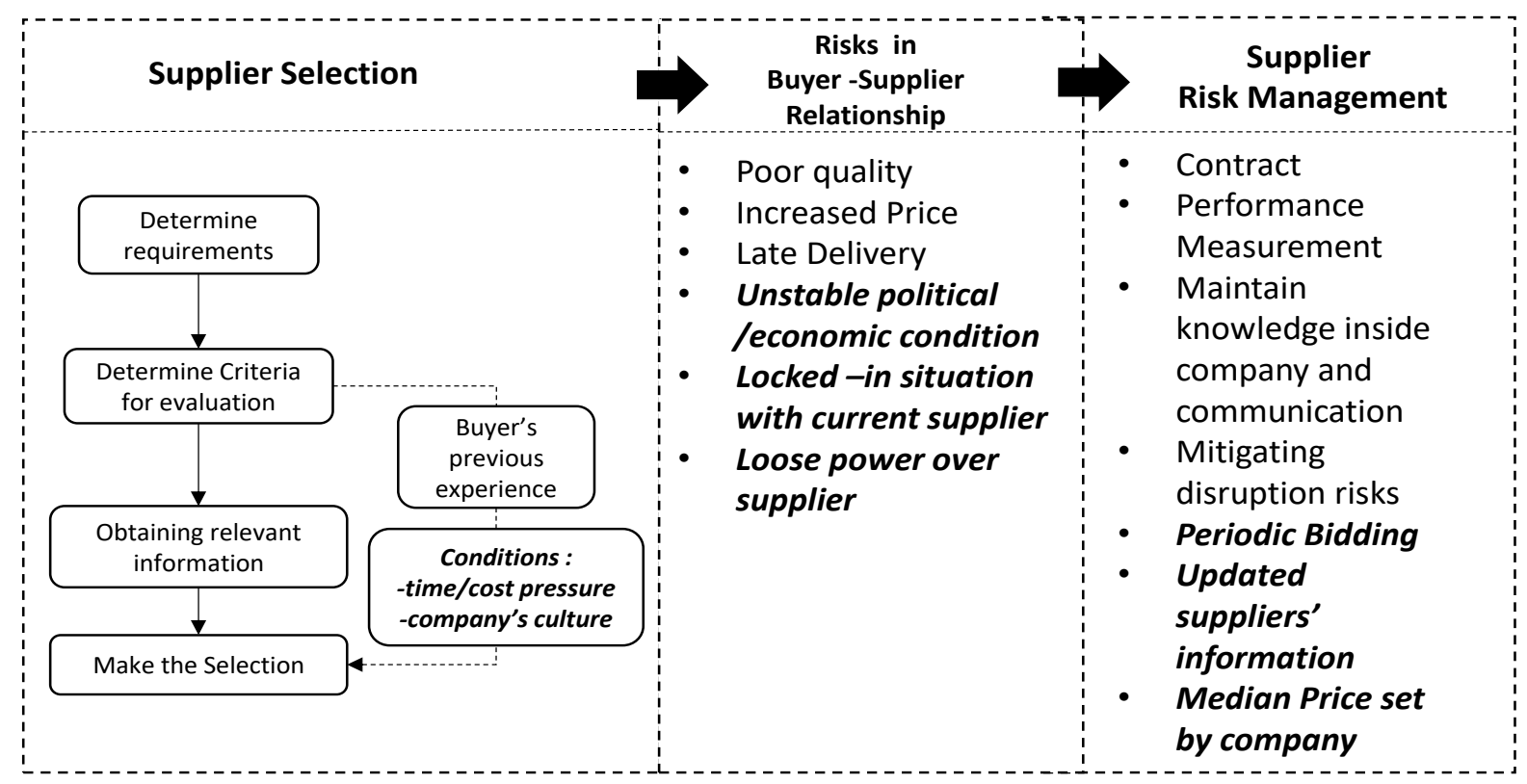

Figure 8. Selective coding (final coding)

blem with perfume suppliers, then why should we have a contract?". The author suggests that the right contract aligns with types of relationship the company need (from SRPM Matrix). Moreover, while a good contract is necessary, proper enforcement is also critical (Barthelemy [21]).

There was a sense of the importance of performance measurement amongst interviewees, even though company 3 stated it is crucial. Nevertheless, they have not done correctly since several limitations, particularly in procurement involvement and IT infrastructure. Performance measurement as a part of a quality management system by linking department (marketing or logistics) rating to the purchasing decision is suggested to implement a better performance measurement system (especially in company 2 and 3). Performance measurement needs to be done by top management, which is proved to have a direct impact on supply chain risk management (Siagian et al. [46]). Even though Company 1 has sufficient infrastructure, but a formalized supplier performance rating did not found, proving (Purdy et al. [47]) argument that having the right infrastructure is not enough. However, people who use and respond to technology is needed. The author suggests Company 1 need to have a more formal performance measurement rating system, as one structured rating method examples from (Schmitz and Platts [9]) (see Table 2).

Periodic re-bidding is a form of control which only done by Company 1. However, Company 1 needs to be careful, as periodic re-bidding can threaten the level of certainty in their relationship. Meanwhile, this method can be implemented by Company 3 to avoid the locked-in relationship with its current $\mathrm{WH}$ provider. 
Moreover, setting the median price done by Company 3 can be seen as adequate to mitigate risks of fuel price instability. However, it is feasible if supply risks are low (a lot of available suppliers), therefore company (as a buyer) has high bargaining power. Nevertheless, companies needs to set the median price carefully, or it may lead to a higher cost. Companies' strategies in managing risks found in Figure 7.

\section{Selective Coding}

In answering how companies choosing their suppliers, a standard view that amongst interviewees were that any supplier selection began from various requirements, and every company have their criteria in evaluating suppliers. However, interestingly, it is found from the interviews that evaluation process not only depends on the criteria they set before, but also time or cost pressure, company's primary preference with current suppliers, or politics inside the company contributing the selection process. For example, if there is a limited time, Company 3 would choose any transporter available, even though it is not the lowest cost. Moreover, Company 1 would prioritise their reliable, current suppliers rather than finding new suppliers. Alternatively, in the case of Company 2, it can be biased and prefer suppliers from the company's origin country when they can.

Once a supplier has been chosen, there are several risks found in portfolio relationship. The first and the most risk deemed by companies are the risks of unperformed suppliers as expected, such as increased price, lower quality, or late delivery. Unperformed suppliers caused by opportunist behaviour by providing the firm with the least satisfactory level of a provision (Lonsdale and Cox [1]). Second, due to unstable politic and economic condition, the risk of a country's stability is a problem. For example, for Company 2, this can impact directly to a higher price of material imported, or how several negotiations in setting the price for transporters due to frequent fuel price changes. The third risk is a locked-in situation, which can be caused by a company's global contract (found in Company 3) or high political reasons (found in Company 2). Fourth, the risk of losing power over the buyer experienced by Company 3, which drawn by (Cox [48]) in a buyer-supplier matrix. This power circumstance is mapped as the level of dependency in the SRPM matrix. Companies need to set relationship positioning strategy from the beginning of the relationship. In supplier risk management, the theme of contract and performance measurement recurred throughout the interviews. An alignment of contract and performance measurement based on what type of materials or services purchased from a particular supplier, and what kind of values expected to get from the relationship set in place are essential (Cousins [49]). Taking key points from interviews and compared it to existing literature, the final selective coding resulted is as below. Yellow boxes showed new findings from the interviews (Figure 8).

\section{Conclusion}

In selecting their suppliers, the companies still only consider operational factors like cost, quality, and delivery to select their suppliers. It is essential to consider conditions such as time/cost pressures and culture inside the company in supplier selection. Moreover, regarding the supplier portfolio, most companies explored have not set different types of relationship based on the service or product purchased. They usually have the same approach for all their suppliers. However, any different types of relationship they choose (arm's length or collaborative), the performance measurement still limited to operations objectives. A formal supplier rating has not found in all companies, let alone supplier development initiatives. It is also interesting to find that no contacts in buyer-supplier found in most companies studied, mainly because they see contracts as a burden that may trouble them in the future.

With this study, the researcher expects to contribute evidence regarding supplier relationship management practices in MNCs operating in Indonesia, resulting a selective coding (Figure 8) adding several factors to current literature. For future research, the author suggests quantitative research with more samples to test findings found from this research. Further, data can be collected both from buyers and suppliers to achieve triangulation.

\section{References}

1. Lonsdale, C., and Cox, A., Outsourcing: A Business Guide to Risk Management Tools and Techniques, Earlsgate Press, 1998.

2. Shy, O., and Stenbacka, R., 'Partial Outsourcing, Monitoring Cost and Market Structure. Canadian Journal of Economics/Revue Canadienne d'Economique, 38(4), 2005, pp. 1173-1190

3. Kang, M., Wu, X., Hong, P., and Park, Y., Aligning Organizational Control Practices with Competitive Outsourcing Performance. Journal of Business Research, 65(8), 2011, pp. 1195-1201.

4. Wilding, R., and Juriado, R., Customer Perceptions on Logistics Outsourcing in the European Consumer Goods Industry. International Journal of Physical Distribution and Logistics, 34(8), 2004, pp. 628-644. 
5. Car, A. S., and Pearson, J. N., Strategically Managed Buyer-supplier Relationships and Performance Outcomes, Journal of Operations Management, Issue 17, 1999, pp. 497-519.

6. Narayanan, S., Narasimhan, R. and Schoenherr, T., Assessing the Contingent Effects of Collaboration on Agility Performance in Buyer-supplier Relationships. Journal of Operations Management, Issue 33-34, 2015, pp. 140-154

7. Cousins, P., Lamming, R., and Squire, B., Strategic Supply Management. 1st ed. Edinburgh Gate: Pearson Education Limited, 2008.

8. MacKerron, G., Kumar, M., Benedikt, A., and Kumar, V., Performance Management of Suppliers in Outsourcing Project: Case Analysis from the Financial Services Industry. Production Planning and Control, 26(2), 2015, pp. 150165

9. Schmitz, J. and Platts, K., Roles of Supplier Performance Measurement: Indication from a Study in the Automotive Industry. Management Decision, 41(8), 2003, pp. 711-721.

10. Sako, M., Prices, Quality and Trust: Inter-firm Relations in Britain and Japan. Cambridge: Cambridge, Univ.Press, 1992.

11. Liu, Y., Luo, Y., and Liu, T., Governing Buyersupplier Relationships through Transactional and Relational Mechanisms: Evidence from China. Journal of Operations Management, Issue 27, 2009, pp. 294-309.

12. Tang, X. and Rai, A., The Moderating Effects of Supplier Portfolio Characteristics on the Competitive Performance Impacts of Supplier-facing Process Capabilities. Journal of Operations Management, Issue 30, 2012, pp. 85-98.

13. De Boer, L., Labro, E., Morlacchi, and Pierangela, A Review of Methods Supporting Supplier, European journal of purchasing and supply management, 2001, pp.75-89

14. Kraljic, P., Purchasing Must Become Supply Management. Harvard Business Review, 1983, pp. 109-117.

15. Gelderman, C. J., and van Weele, A. J., Purchasing Portfolio Models: A Critique and Update. The Journal of Supply Chain Management, 41(3), 2005, pp. 19-28.

16. van Weele, A., Purchasing and Supply Chain Management: Analysis, Planning and Practice. 2nd ed. London: Thomson Learning, 2000.

17. Gelderman, C. J., and Weele, A. J., Strategic Direction through Purchasing Portfolio Management: A Case Study. Journal of Supply Chain Management, 38(1), 2002, pp. 30-37.

18. Talluri, S. and Narasimhan, R., A Methodology for Strategic Sourcing. European Journal of Operational Research, 154(1), 2004, pp. 236-250.

19. Cousins, P. and Lawson, B., The Effect of Socialization Mechanisms and Performance Measurement on Supplier Integration in New Product Development. British Journal of Management, 18(3), 2007, pp. 311-326.
20. McIvor, R., The Outsourcing Process. Cambridge: Cambridge University Press, 2005.

21. Barthelemy, J., The Seven Deadly Sins of Outsourcing. Academy of Management Executive, 17(2), 2003, pp. 87-100.

22. Golmohammadi, D., and Mellat-Parast, M., Developing a Grey-based Decision-making Model for Supplier Selection. International Journal of Production Economics, 137, 2012, pp. 191-200.

23. Caniels, M. C. and Roeleveld, A., Power and Dependence Perspectives on Outsourcing Decision. European Management Journal, 27, 2009, pp. 402-417.

24. Leonidou, L. C., Industrial Buyers' Influence Strategies: Buying Situation Differences. Journal of Business and Industrial Marketing, 20(1), 2005, pp. 33 - 42.

25. Tang, C., Perspectives in Supply Chain Risk Management. International Journal of Production Economics, 103, 2006, pp. 451-488.

26. Olsen, R. F., and Ellram, L. M., A Portfolio Approach to Supplier Relationship. Industrial Marketing Management, 26, 1997, pp. 101-113.

27. Tang, C. S., Supplier Relationship Map. International Journal of Logistics: Research and Applications, 2(1), 1999, pp. 39-56.

28. Razzaque, M. A. and Sheng, C. C., Outsourcing of Logistics Functions: A Literature Survey. Outsourcing of Logistics Function, 28(2), 1998, pp. 89 - 107.

29. Hitt, M. A., Dacin, M. T., Levitas, E., Arregle, J.L., \& Borza, A.., Partner Selection in Emerging and Developed Market Context: Resource-Based and Organizational Learning Perspectives. Academy of Management Journal, 43(3), 2000, pp. 449-467.

30. Khanna, T., Palepu, K. G., and Sinha, J., Strategies that Fit Emerging Markets. Harvard Business Review, 83(6), 2005, pp. 63-84.

31. Mc.Ivor, R., Humphreys, P., McKittrick, A., and Wall, T., Performance Management and the Outsourcing Process. International Journal of Operations and Production Management, 29(10), 2009, pp. 1025-1048.

32. Cousins, P. D., Lawson, B. and Squire, B., Performance Measurement in Strategic Buyersupplier Relationship. International Journal of Opetaionsand Production Management, 28(3), 200, pp. 238-258.

33. Sodhi, M., and Tang, C. S., Managing Supply Chain Risk. London: Springer, 2012.

34. Quinn, J. B., and Hilmer, F. G., Strategic Outsourcing. Sloan Management Review, 1994, pp. 43-55.

35. Lawson, B., Tyler, B. B., and Cousins, P. D., Antecendents and Consequences of Social Capital on Buyer Performance Improvement. Journal of Operations Management, 26, 2008, pp. 446-460. 
36. Chopra, S., and Sodhi, M. S., Reducing the Risk of Supply Chain Disruptions. MIT Sloan Management Review, 55(3), 2014, pp. 73-80

37. Saunders, M., Lewis, P., and Thornhill, A., Research Methods for Business Students. 6th ed. Essex: Pearson Education Limited, 2012.

38. Yin, R. K., Case Study Research: Design and Method. 3rd ed. Pennsylvania: SAGE. 2003.

39. Denscombe, M., The Good Research Guide for Small-scale Social Research projects. 5th ed. Leicester: McGraw-Hill.,2014.

40. Benbasat, I., Goldstein, D. K., and Mead, M., The Case Research Strategy in Studies of Information Systems. Management Information Systems Research Center University of Minnesota, 11(3), 1987, pp. 369-386.

41. Voss, C., Tsikriktsis, N., and Frohlich, M., Case Research: Case Research on Operations Management. International Journal of Operations and Production Management, 22(2), 2002, pp. 195-219.

42. Corbin, J. M., and Strauss, A. L., Basics of Qualitative Research: Techniques and Procedures for Developing Grounded theory. 3rd ed. Thousand Oaks, CA: Sage, 2008.

43. Kannan, V. R., and Tan, K. C., Supplier Selection and Assessment: Their Impact on Business Performance. The Journal of Supply Chain Management, 38(3), 2002, pp. 11-21.
44. Ellram, L. M., The Supplier Selection Decision in Strategic Partnerships. International Journal of Purchasing and Materials Management, 26(4), 1990, pp. 8-14.

45. McCutcheon, D., and Stuart, F. I., Issues in the Choice of Supplier Alliance Partners. Journal of Operations Management, 18, 2000, p. 279-301

46. Siagian, H., Tarigan, J.H. Z., and Hee, H. T., The Effect of Top Management Involvement on Supply Chain Risk Management through BuyerSupplier Relationship, Jurnal Teknik Industri, 2018, pp. 105-112.

47. Purdy, L., Astad, U. and Safayen, F., Perceived Effectiveness of the Automotive Supplier Evaluation Process. International Journal of Operations and Production Management, 14(6), 1994, pp. 91-103

48. Cox, A. Understanding Buyer and Supplier Power: A Framework for Procurement and Supply Competence. The Journal of Supply Chain Management, 37(1), 2001, pp. 8-15.

49. Cousins, P. D., A Conceptual Model for Managing Long-term Inter-organisational Relationships. European Journal of Purchasing and Supply Management, 8, 2002, pp. 71-82. 